affected. Head and Campbell, ${ }^{6}$ in 1900 , pathologically demonstrated the presence of micro-organisms in the nerve radicles involved, and contended that herpes zoster was an acute specific disease. This was later experimentally proved by Rosenow and Oftedahl, ${ }^{7}$ in their work on specific streptococci selection, by isolating streptococci from tonsils, pyorrheal abscesses, sputum and spinal fluid in man with herpes, and producing herpes, with corresponding ganglionic lesions, by animal inoculation with these strains of organisms.

As to chickenpox, nothing has ever been definitely determined etiologically. Tyzzer, ${ }^{8}$ in a histopathologic study of chickenpox vesicles, found certain bodies enclosed in the nuclei and cytoplasm of the cells involved. These he considered typical of chickenpox, but he was unable to produce new lesions by their inoculation, and had to consider them as nonparasitic. Keysselitz and Mayer ${ }^{9}$ believed that the inclusion bodies of chickenpox were analogous to cytoryctes and that they were not in themselves definitely parasites, but contained the infective virus.

Very little else has been discovered.

\section{COLORIMETRIC DETERMINATION OF REACTION OF BACTERIOLOGIC MEDIUMS AND OTHER FLUIDS}

\author{
GEORGE D. BARNETT, M.D. \\ Passed Assistant Surgeon, U. S. Naval Reserve force \\ AND \\ HERBERT S. CHAPMAN, M.D. \\ Assistant Surgeon, U. S. Navy \\ SAN FRANCISCO
}

- The colorimetric methods in common use for determining and adjusting the reaction of bacteriologic mediums and other fluids involve the use of standard solutions of known hydrogen ion concentration. A variety of such solutions has been described, and they are readily prepared by any one having a moderate chemical equipment and ability. Just now, however, many men with comparatively little chemical training are confronted with problems of this nature, and the method here described has therefore been devised to accomplish a fairly accurate determination of hydrogen ion concentration without the necessity of preparing standard solutions or of depending on those prepared by others. We are here concerned only with reactions lying between 7.0 and 8.0 , and only phenolsulphonephthalein has been used as an indicator. Other indicators and other ranges of acidity will be investigated later.

In this method use is made of the principle of superimposing the two extreme colors of the indicator, as used by Clark and Lubs, ${ }^{1}$ following Salm, ${ }^{2}$ in determining the so-called half-transformation points of indicators. Within the range of its transition from red to yellow, we may regard the observed color of a

6. Head and Camplell:: The Pathology of Herpes Zoster and Its Bearing on Sensory Localization, Brain, London, 1900, 23, 353 .

aring on Sensory Localization, Brain, London, 7. Rosenow, E. C., and Oftedahl, S.: The Etiology and Experimental
Production of Herpes Zoster, THE Jour at A. M. A., June, 12, 1915, Production of Herpes Zoster, The Jour N

p. 1968; Jour. Infect. Dis., 1916, 18, 477 . 8. Tyzzer: Histology
Research, 1906, 14, 361 .

Research, 1906, 14, 361. 9. Keysselitz and Mayer: Zur Aetiologie der Varicellen, Arch. f Protistenk, Jena, 1909, 14, 113.

1. Clark and Lubs: Jour. Bacteriol., 1917, 2, 109, 191.

2. Salm: Ztschr. f. phys. Chem., 1906, 57, 471 phenolsulphonephthalein solution as composed of a definite amount of red plus a definite amourit of yellow, and such a color may be exactly duplicated by superimposing the extreme red and the extreme yellow of the indicator in proper-concentrations. Thus, if to one test tube we add 5 c.c. of dilute acid, and to another similar tube 5 c.c. of dilute alkali, and to each add 5 drops of phenolsulphonephthalein solution, a bright yellow will be produced in the first tube and a bright red in the other. But if we look toward the light through both tubes, a color will be observed that is half way between the yellow and the red. In fact, it will be identical with the color produced by 10 drops of the phenolsulphonephthalein solution in 5 c.c. of a standard solution having a $p_{\mathrm{H}}$ of 7.9. This is the half transformation point, and is a definite constant for this indicator. But if instead of using equal amounts of indicator in each of the two tubes we vary the partition of the 10 drops of indicator between them, then by superimposing each pair and viewing them by transmitted light, a series of colors will be produced which will cover the range of usefulness of the indicator; and once such a series is "calibrated" against solutions of known hydrogen ion concentration, it may be used as a standard series for the determination of unknown reactions.

Results obtained by such a procedure in the case of phenolsulphonephthalein, comparison being made with phosphate-solutions prepared according to Sörensen," are as shown in the accompanying table.

\begin{tabular}{ccc} 
RESULTS & WITH & PHENOLSULPHONEPHTHALEIN \\
$\begin{array}{c}\text { Acid Tubes } \\
\text { Phenolsulphonephthalein } \\
\text { Solution, Drops }\end{array}$ & $\begin{array}{c}\text { Alkali Tubes } \\
\text { Phenolsuiphonephthalein } \\
\text { Solution, Drops }\end{array}$ \\
9 & $\mathbf{1}$ & $0 \mathrm{pH}$ \\
8 & 2 & 6.9 \\
7 & 3 & 7.5 \\
6 & 4 & 7.7 \\
5 & 5 & 7.9 \\
4 & 6 & 8.1 \\
\hline
\end{tabular}

\section{OUTLINE OF METHOD}

Apparatus and Chemicals Required.-1. Clean test tubes. These must be of approximately the same diameter. An equal volume of water is measured into a number of tubes, and fifteen or twenty are selected for use in which the water stands at about the same level.

\section{A 5 c.c. pipet.}

3. A medicine dropper drawn out to a fairly fine point.

\section{A buret.}

5. An indicator solution. A convenient solution (0.01 per cent.) of phenolsulphonephthalein is prepared by diluting 1 c.c. of the usual solution used for kidney function tests ( 1 c.c. $=6 \mathrm{mg}$.) to 60 c.c. with distilled water. No accuracy is necessary, provided the same solution is used throughout.

6. Roughly normal and twentieth normal sodium hydroxid.

7. Hydrochloric or sulphuric acid.

Preparation of Standard Color Series.-Twelve test tubes are placed in two rows of six. Into each tube of one row 5 c.c. of dilute alkali are placed. (The twentieth-normal sodium hydroxid may be used, or any solution sufficiently alkaline to bring out the maximum red color of the indicator.) Into each tube of the other row, 5 c.c. of very dilute acid are placed (One

3. Sörensen and Palitzsch: Biochem. Ztschr., 1910, 24, 387. 
drop of concentrated hydrochloric or sulphuric acid to 100 c.c. of distilled water is sufficiently strong. Strong acid is to be avoided in the case of phenolsulphonephthalein, on account of its secondary color change.) Into the six acid tubes, 9, 8, 7, 6,.5 and 4 drops, respectively, of indicator are placed. Into the six corresponding alkali tubes, $1,2,3,4,5$ and 6 drops of indicator are placed. If the dropper is held vertically, the drops will be practically of a size. Each pair of tubes thus contain 10 drops of indicator between them, and the series of six pairs, when viewed by transmitted light, will correspond to $p_{\mathrm{H}}$ values of $6.9,7.2,7.5,7.7,7.9$ and 8.1 (as in the table) when compared with 5 c.c. volumes of any solution containing 10 drops of the same indicator solution. In order to determine the hydrogen ion concentration of an unknown solution whose reaction lies within this range, 5 c.c. of it are placed in a test tube, 10 drops of indicator are added, and its color is compared with those of the six pairs of tubes. The use of a second tube containing distilled water to form a pair with the unknown is to be recommended, but does not appear to affect the results appreciably. The color series prepared in this manner is as accurate as that yielded by standard phosphate or other solutions when used in a similar apparatus, and can be prepared anywhere in a few minutes without the use of graduated apparatus or accurate quantitative solutions of any kind. As noted by Clark and Lubs, ${ }^{1}$ the use of pairs of test tubes is a device which is "optically very imperfect, but it works fairly well."

\section{TITRATION OF MEDIUMS}

One c.c. of the medium to be titrated is added to 4 c.c. of distilled water in a test tube. Ten drops of indicator are added, the color is compared with the color standards if it is desired to determine the initial reaction, and titration to the desired hydrogen ion concentration with twentieth-normal sodium hydroxid is performed. Fifty times the amount used will represent the amount of normal sodium hydroxid to be added to 1 liter of medium. If in carrying out the titration sufficient sodium hydroxid solution is added so that the indicator color is appreciably diluted, the end-point tubes of the comparator should be filled to a similar volume before the final comparison is made. If desired, in comparing colors, use may be made of the block described by Hurwitz, Meyer and Ostenberg, ${ }^{4}$ though practically it has not been found to increase the accuracy appreciably. This is a wooden block in which two pairs of adjacent holes have been drilled to receive two pairs of test tubes. The holes are connected by slits so that each pair may be viewed by transmitted light. In this procedure one pair of holes would contain the acid-alkali pair chosen for an end-point, and the other the diluted mediums and a tube of distilled water. Compensation for colored fluids can usually be accomplished according to the principle introduced by Walpole, ${ }^{5}$ by using in one row of the color standard series 5 c.c. amounts of the fluid made acid (or alkaline).

4. Hurwitz, Meyer and Ostenberg: Bull. Johns Hopkins Hosp., $1916, \mathbf{2 7}, 16$

5. Walpole: Biochem. Jour., 1910-1911, 5, 207.

Morbidity.-With the full cooperation of the public we may expect that morbidity and mortality rates will decrease; for the prevention of morbid conditions due to wrong living rests with the individual, who understands.-Health News.

\section{Clinical Notes, Suggestions, and New Instruments}

\section{ARTIFICIAL RESPIRATION IN ASPHYXIA NEONATORUM}

Clarence L. Heald, M.D., Cedar Rapids, Iowa

Of the classic methods of artificial respiration in asphyxia neonatorum, mouth-to-mouth insufflation has proved more efficient than the methods dependent on manipulation of the child. The manipulative methods of Prochownick (rhythmic compression of the child's chest in inverted suspension), rhythmic flexion and extension of the child's body, and Schultz' swingings are all useful in asphyxia livida, but in the more critical condition of asphyxia pallida, mouth-to-mouth insufflation or insufflation through a tracheal catheter will frequently succeed after these methods have failed.

There are, however, serious objections to mouth-to-mouth insufflation: 1. The delicate air vesicle may be ruptured. Bichat has proved the possibility of blowing air into the vessels near the heart if too much force is used. 2. There is danger of infection of the child by the operator. 3. The insufflated air has already been deprived of much of its oxygen, and is laden with carbon dioxid. 4. The air cannot be changed with sufficient rapidity to oxygenate the blood. 5. The method is laborious and cannot be kept up long by one person. 6. In asphyxia pallida this, as well as all the indirect methods of artificial respiration, is too often futile.

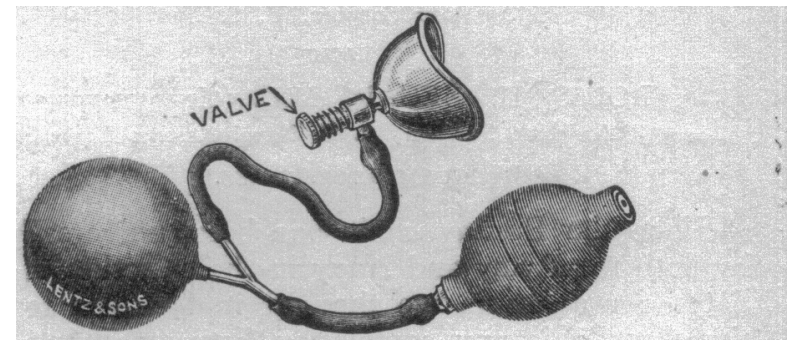

Instrument for artificial respiration in asphyxia neonatorum.

Some years ago I had an instrument made for artificial respiration in infants which has been very satisfactory in these cases. It consists of a syringe bulb connected by rubber tubing with an air valve in the dome of a small helmetshaped mask, and by a $Y$ tube with an ordinary rubber toy balloon. The latter serves as a reservoir, and, as its expansile tension is about $8 \mathrm{~mm}$. of mercury, it prevents the air pressure in the child's lungs from rising above that point. It also produces a uniform, steady flow of air.

It is essential that the upper respiratory passages be clear before artificial respiration is started. In any case, therefore, in which it is probable that the placental circulation has been cut off before the head is born, as in breech presentation or prolapse of the cord, a tracheal catheter should be introduced. and the trachea cleared by suction. After the mouth is cleared out with the gauze-covered finger, a thread on a needle is passed through the tongue to hold that organ well forward, but not outside of the mouth. A towel is wrapped snugly, but not tightly, about the child's abdomen to prevent air from entering the stomach. While an assistant keeps the balloon inflated by compressing the bulb, the operator holds the mask, with its long diameter transversely, over the child's mouth, including the chin, but not the nose. With the index finger of the same hand he manipulates the piston of the air valve, pressure on which allows the air to flow. With the finger and thumb of the other hand he alternately compresses and releases the nostrils through which expiration takes place. Pressing the air valve piston, at the same time compressing the nostrils to prevent escape of air, he inflates the lungs. Simultaneous release of the air valve piston (stopping the air flow) and release of the nostrils allow expiration to 